\title{
Fernando Valencia
}

\author{
Cite as: CMAJ 2020 December 7;192:E1733. \\ doi: 10.1503/cmaj.202619
}

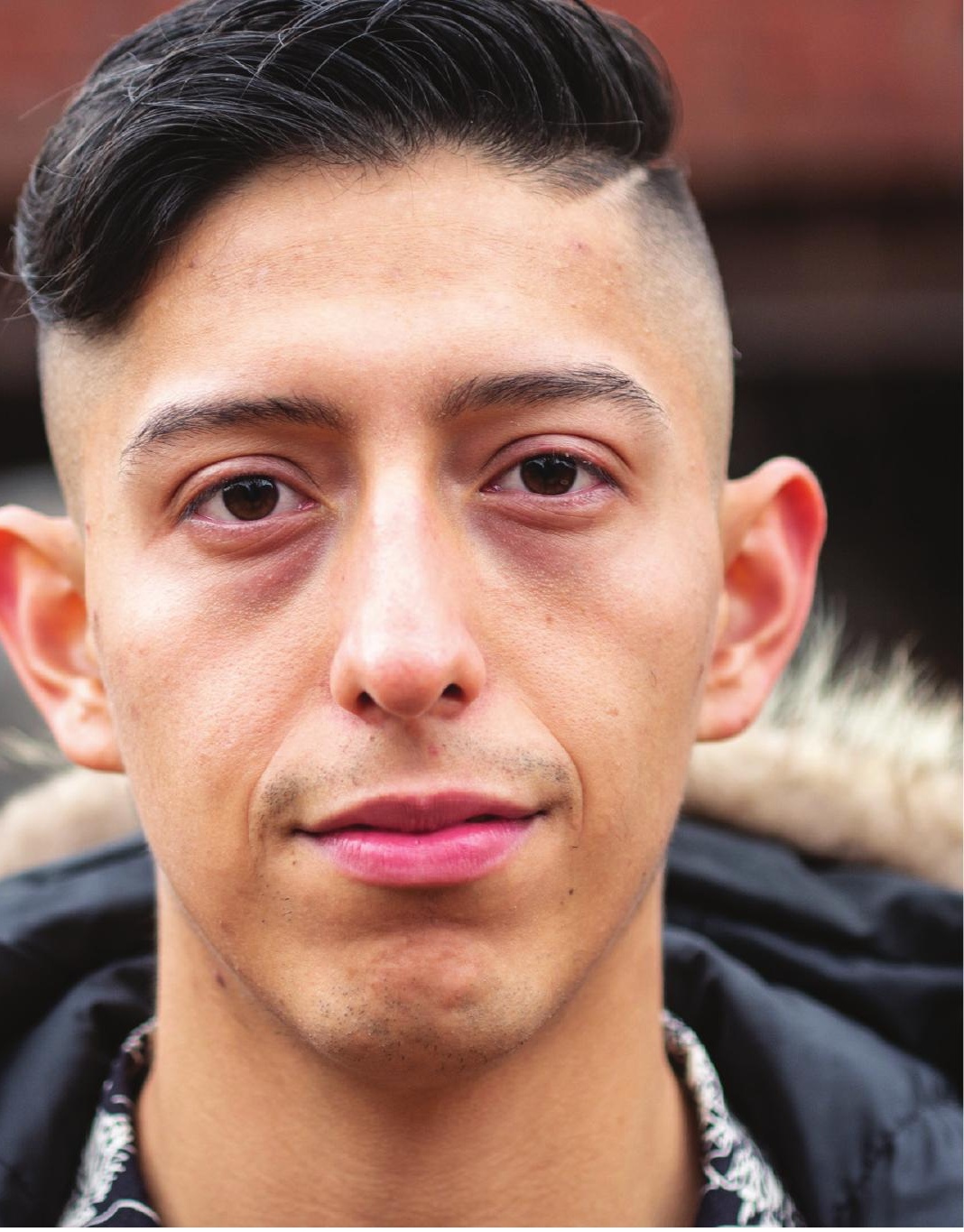

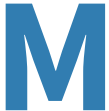
y dad, Ricardo, is 63 years old. Two years ago, he suffered a severe subarachnoid hemorrhage while at work. We did not know if he would make it.

It's been a long recovery, but he slowly got better. He went from the hospital to a palliative care unit in a partial coma. When he got there, he could not walk. Through physio and my family helping out, he slowly regained his ability to get up. His cognition improved dramatically. Toward the end of his time there, he could even take a couple of steps.

But this seemed to spark administrative concerns more than celebrations at his facility. Where was he going to go now that he was getting better?

My dad's goal of walking seemed like it was becoming more realistic. We were hopeful he would get into a rehab facility. An earlier application was rejected, but he was not even able to sit up then. This time, we were told his MoCA (cognitive assessment) showed no improvement so he was ineligible. This did not make sense to us - no better than when he was in a coma? I realized the test was administered in English. My dad speaks Spanish.

Unfortunately, the MoCA was never repeated because he got a bed in longterm care. We had made longterm care choices when my dad was much sicker, and we could not reverse course even though this now seemed so inappropriate. Most team members agreed that my dad should go to rehab, but they were powerless to stop his transfer.

Last month, he fell out of his wheelchair and broke his hip. The hospital team said he was an excellent rehab candidate but that long-term care patients were ineligible to apply. So they sent him back to longterm care.

My dad is not happy where he is. He has no social interaction. Most of the residents have advanced dementia. My family is working tirelessly to figure out other options with little help.

We are so grateful for our health care system and what it's done for my dad. It saved his life. But the segments of his

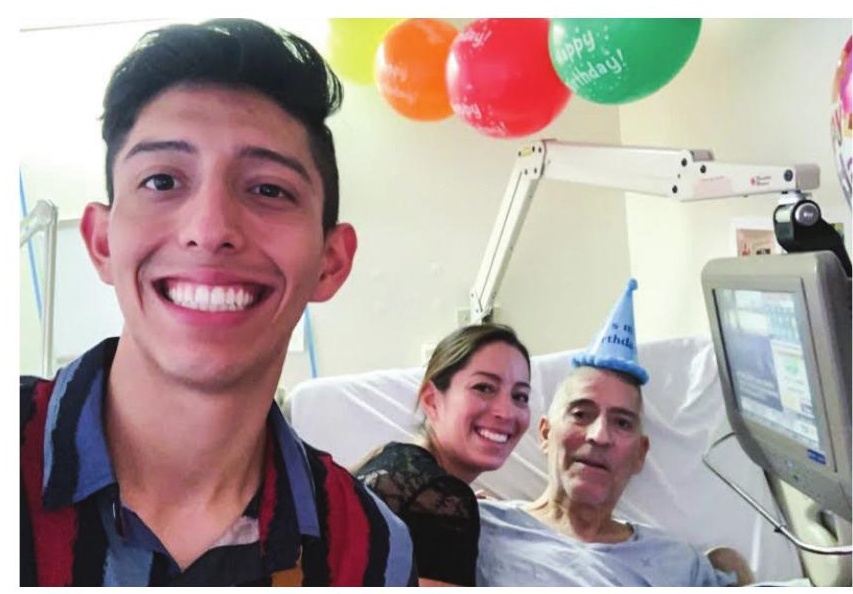

care were so disconnected. Each facility's main goal was to get us discharged to the next place - not to assess his wants or meet his needs. 